\title{
Mitigating and adapting to climate change: attitudinal and behavioural challenges in South Asia
}

\author{
Shahzad Alvi \\ Department of Economics, School of Social Sciences and Humanities (S3H), \\ National University of Sciences and Technology (NUST), Islamabad, Pakistan, and \\ Umer Khayyam \\ Department of Development Studies, School of Social Sciences and \\ Humanities (S3H), National University of Sciences and Technology (NUST), \\ Islamabad, Pakistan
}

\begin{abstract}
Purpose - This study aims to examine peoples' perception of climate change. It assessed their attitude, behavioural motivation for mitigating and adapting to climate change in the two capital cities of South Asia: Islamabad in Pakistan and Dhaka in Bangladesh.

Design/methodology/approach - This study used the quantitative research technique based on responses of 800 close-ended questions embedded in a close-ended questionnaire, which were filled-out from randomly selected sample of respondents. The primary data was analysed and presented through tabulation. For binary dependent variables, the standardised logistic coefficients were projected for more reliable estimates.

Findings - The findings reveal that the population of both capital cities have a low personal perception of climate change. Also, the dwellers of both cities have a low level of motivation to take mitigative and adaptive measures against climatic hazards. The results of the logistic regression model further indicate that the people who believe that climate change is a threat to their lives are more likely to adopt mitigative and adaptive strategies. This mostly applies to the people with a relatively higher income and education level.

Research limitations/implications - This study implies to create awareness and sensitise the local community in both the capitals and beyond through information dissemination. Further, the availability of toolkits to handle emergencies remains imperative in registering attitudinal and behavioural changes to reduce the impacts of climate variability in poor localities.

Originality/value - This research study analysed the link between climate change mitigation and energy conservation from the societal attributes of perception, motivation, attitude and behaviour, which remains essential for community-based mitigation against climatic hazards.
\end{abstract}

Keywords Attitudes, Climate change, Behavior, Mitigation, Adaptation, South Asia

Paper type Research paper

(c) Shahzad Alvi and Umer Khayyam. Published by Emerald Publishing Limited. This article is published under the Creative Commons Attribution (CC BY 4.0) licence. Anyone may reproduce, distribute, translate and create derivative works of this article (for both commercial and noncommercial purposes), subject to full attribution to the original publication and authors. The full terms of this licence may be seen at http://creativecommons.org/licences/by/4.0/legalcode

The authors of this study are thankful to surveyors, both in Dhaka and Islamabad, for the quality of data collection on a volunteer basis. Thanks also to the journal editor and the anonymous reviewers for the in-depth review and comments that have greatly improved this manuscript.

Received 30 August 2019 Revised 21 February 2020 9 April 2020 14 April 2020 28 April 2020 Accepted 7 May 2020 
IJCCSM

12,4

\section{Introduction}

Anticipating future scenarios to predict the environmental, ecological or societal loses as a result of climate change is an unprecedented challenge for humanity. Climate change is due to the result of complex natural and contentious anthropogenic changes that have global as well as regional impacts. Thus, the threats associated with climate change because of continuous changing climatic patterns, hinder national actions against the existent and possible threats (Schofield, 2011). It is pertinent that the adverse impacts of natural disasters [1] are not confined to only one sector. They are extended to physical as well as an ecological system because sudden and drastic changes in both the systems are life threatening (Gregory et al, 2004). The adversities of climate change are found mainly in societies that are already vulnerable [2] and have limited resources, which further undermine their earning opportunities (McCusker and Carr, 2006). The loss of already degraded means of earning in both the formal (e.g. jobs) and informal (e.g. agricultural production) damage the life cycle at an unprecedented rate (Chau $e t$ $a l$. 2013). Also, the exceptional rise in the occurrence of calamities is declaring a significant impression across the socio-economic and politico-cultural domain of poor societies. It destroys human settlements, dismantles roads and bridges and creates havoc. It causes a high renovation cost, which is mostly unaffordable for the poor societies (Khan, 2013).

The climate change and related climate variability is expected to further intensify global socio-economic disparities. The anticipated effects of climate change can be categorised as having either a direct or indirect impact, which might appear as a simple cause-and-effect dichotomy, but constitutes a complex and multifarious continuum. The adverse effects of climate change on the global system are thus enormous and are getting severe as the level of greenhouse gases (GHGs) sharply increases. The anticipated adverse effects of climate change include the degradation of the social fabric, economic losses and losses of human lives, which results in an increased level of morbidity and mortality. Studies are currently being undertaken in an attempt to examine the scale and types of potential impacts of climate change and our survival (Furgal et al, 2002). The underdeveloped countries, although are not harming the natural environment much by (e.g. producing less GHGs than developed countries) are disproportionately affected by climate change (Wiley and Gostin, 2009). The poor people in the developing countries are particularly at a high risk of - and constitute to a big portion of health hazards that are associated with climate change. Besides, many socio-economic loses in underdeveloped countries are in part due to their exposure to climatic change (Dhiman et al., 2010). The potential of future harm by the climatic events acts as a warning bell, to plan and to cater to the long-lasting adverse impacts of climatic hazards (Khan, 2013). So, in the drastic times of climate change, mitigation [3] is recognised as a necessity, especially in the developing countries (Mbow et al., 2014). The community-based mitigation measures are planned to respond to climatic threats and build a resilient system (McMichael and Kovats, 2000, McCarthy et al, 2001). Yet, this reactive strategy has its limitations, as it fails to help localities to prepare in advance to address the impacts of climate change.

The third-world societies need proactive response strategies, which should rely on community participation. This local or bottom-up-oriented adaptation strategy is based on the capabilities of the vulnerable societies and how they react to climatic hazards in advance (Furgal et al, 2002). There is a dire need for such pre-emptive approaches because the poorer countries have inadequate capabilities to react to climatic hazards (Adger, 2006). These underdeveloped countries take adaptive [4] measures against climatic risks. These individualistic and collective efforts are dependent upon locals' social capital; amongst other efforts. The societal capital is critical for constructing resilience in the local populace. This capital also helps to foster adaptive measures against environmental stressors. It is a reality that little attention is paid so far to explore the societal matrix as an adaptive measure against climatic hazards 
(Adger, 2010). However, community-based adaptation measures have started gaining significant international attention on how communities respond to the increasing threats and pressures of climate change (Clarke et al., 2019). As community-based adaptations are gaining much attention, an adaptation strategy becomes an inevitable and urgent priority for the global societies (Betzold, 2015). It is also becoming internationally recognised as top-down or centralised adaptation approaches that are overwhelmed with inefficiencies (Ayers and Forsyth, 2009). The profound adaptation measure at a community level is based solely on the understandings of local contexts, priorities and the need of the affected local population, which are then based on active local-based initiatives (McNamara, 2013).

So, to plan and execute effective mitigation and adaptation strategies to reduce the adverse impacts of climate change, there exists a dire need to study the behavioural and attitudinal status of communities where such strategies are required (McMichael and Woodruff, 2004). It is because of this need that a baseline research study is crucial to develop effective mitigation and adaptation in poor communities. This is due to underdeveloped societies' exposure and vulnerability to climatic threats. To develop effective mitigative and adaptive strategies, cooperation from the local population is indispensable, as top-down mitigative and adaptive strategies alone have failed to tackle the adversities of climate change (Semenza et al., 2008). Similarly, in South Asia, Pakistan and Bangladesh, which are home to a large population, are faced with frequent natural calamities and so require community-oriented reactive and proactive strategies.

Pakistan is amongst the top ten most vulnerable countries facing climate change. The country is exposed to a variety of natural hazards, including earthquakes, floods, cyclones, droughts and landslides (WDR, 2003). The country faces enlarged socio-economic damages at varying degrees. So far, the poor populace of Pakistan has suffered from losses to property and lives (Abuzar et al., 2016). The rising level of damages because of natural calamities are coupled with rapid population growth and unrestrained development that can increase the vulnerability of any society towards natural hazards. Thus, the increased vulnerability towards natural hazards is projected by unprecedented losses to property and inhabitants. The country has faced deaths in millions, followed by damage to economic capital in billions of dollars (WDR, 2003).

Similarly, topography and (disaster-prone) geographical positioning place Bangladesh at the brink of natural disasters that are further intensifying over time (Alam, 2017). The country consists of more than 230 rivers, coupled with vast waterways that are dragging the country to become the most vulnerable to climate change in South Asia. This reality is linked with social and economic conditions, amongst others (e.g. escalating population and poverty) (WB, 2013; Schellnhuber et al., 2013; Shahid and Behrawan, 2008). The country is consistently facing extreme climatic hazards, which are based on floods, droughts, salinity, water shortage, storms, etc. (WB, 2013; GoB, 2010). These disastrous events are found to have a negative impact on the economic, social and political conditions of the country, which in some cases result in catastrophic loss of lives and livelihoods (Ahmed, 2015; Alam, 2016). These outcomes confirm the vulnerability of the local societies in Bangladesh (Alam et al., 2016). Thus, mitigation and adaptation strategies at the community level are the needed in South Asia. The region (comparatively) remains the most affected geographical area that feels continuous changes in the natural climatic patterns. Such changes are already leading to disastrous situations in both Bangladesh and Pakistan, and there exists no reference to understand local perspectives in mitigating against the adverse impacts of increasing dangers due to climate change. This is because climate change vulnerability cannot exist and flourish in isolation. It is always dependent upon social, economic and biophysical attributes (Alam, 2017), which transform societal attitudes and behaviour towards climatic hazards. 
IJCCSM

12,4

480

Moreover, it is the societal attitudes and behaviour that build and transform collective mitigative and adaptive strategies against climate change and its impacts. Thus, considering the alarming situation presented above, this study aims to provide a local perspective and an analysis of the attitudinal and behavioural traits that remain the sine qua non in mitigative and adaptive strategies of poor communities in South Asia. This study attempts to provide answers to the flowing research questions (RQs):

RQ1. What are the locals' perceptions about climate change associated risk in Islamabad and Dhaka?

$R Q 2$. What is the level of mitigative and adaptive behaviour of the locality to minimise climate change hazards?

RQ3. What is the level of personal motivation to mitigate against climate change impacts through energy conservation?

RQ4. What are the obstacles to energy conservation in Islamabad and Dhaka?

\section{Conceptual framework}

This study has conceptualised climate change, considering it as a natural phenomenon induced by anthropogenic factors and posing adverse (direct and indirect) impact on the socio-economic fabric of all human society. These climate change impacts are considered directly proportional to high exposure to adverse events and the local people's vulnerability to save themselves from the hazards of climatic changes. As a result, such impacts propel societies to mitigate against and adapt at the individual, household and societal level to combat the dangers of climate change. Nevertheless, for such mitigative and adaptive measures to be successful, the decisive factors remain: local perceptions of climate change (agreement levels on the phenomenon's existence), personal motivations to apply mitigation and adaptation strategies (proactive willingness to prepare methods and tools), a dedicated attitude (to alter or refine ideas and strategies against climate change hazards), and a positive change in (individual and societal) behaviour as well as short- and long-term actions that will aid in the reduction of pollution and an increase in carbon sinks (Figure 1).

\begin{tabular}{|ll}
\hline Flood & $\square$ Earthquake \\
$\square$ Local Storm/Tropical Cyclone & $\square$ Avalanche/Landslide \\
$\square$ Extreme temperature & $\square$ Epidemic \\
$\square$ Drought & \\
\hline
\end{tabular}

Figure 1.

Number of natural disaster events in Pakistan since 1900. Created by author, adapted from
71
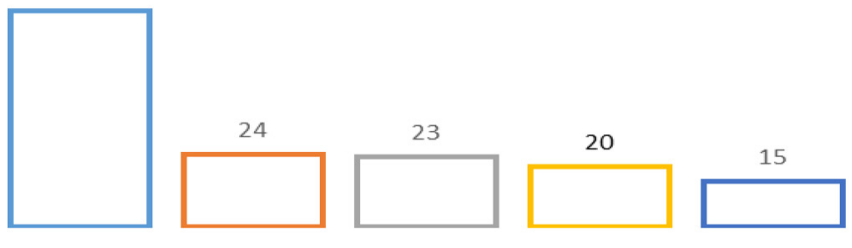

10

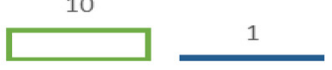

Source: OCHA, 2010 
- Perception: Perception is an active mental process. It contains the selection, structuring and interpretation of any information and gives it a meaning for inferences (Rollinson, 2008). It defines the way of how people perceive any information and react to it (Beck and Kieser, 2003).

- Motivation: Motivation is the reason to act or behave. It varies from situation to situation. It is also referred to as the perceived self-efficacy that defines people's beliefs in their ability and capability to influence or react against any event that harm their lives (Bandura, 2006).

- Attitude: It is a composition of beliefs, norms and stereotypes which show an intention to act against any harm. Attitude reflects an individual's behaviour in any course (Kaise et al., 1999).

- Behaviour: It is the action - a practical term. The behaviour of humans is based on the knowledge or rational thought that is intended for a pre-planned and desirable outcome (Akintunde, 2017).

Both attitude and behaviour are based on the broader structure of the theoretical construct. Attitude provides a base and behaviour defines an act to make strategic decision, either made by an individual, groups or by both (Rollinson, 2008). So, both attitude and behaviour, which are dependent upon individual and societal perceptions and motivation, are the decisive factors to take mitigative and adaptive measures against climate change.

\section{Research methodology}

\subsection{Study area and sampling design}

This research study has been conducted in two capital cities of the South Asian region, namely, Islamabad (Pakistan) and Dhaka (Bangladesh). These two capital cities were chosen because they represent every segment of society and consist respondents of each region of various ethnic and cultural backgrounds. This will enable us to generalise the results in other regions as well. Islamabad is located at $33.6844^{\circ} \mathrm{N}, 73.0479^{\circ} \mathrm{E}$ and Dhaka is at $23.8103^{\circ} \mathrm{N}, 90.4125^{\circ} \mathrm{E}$. The total areas of Islamabad and Dhaka equate to 906.5 and $306.4 \mathrm{~km}^{2}$, respectively (GeoDetos, 2018; Latitude, 2015) (Figure 2). A questionnaire was developed by taking a step-by-step approach to coming up with an effective means to collect data that will answer our RQs. First, several hypotheses were developed as per the research goals. The questions included in the questionnaire aim to systematically test these hypotheses. Second, to keep the analysis simple and understandable for the vast audience, dichotomous questions were used. It is also the quickest to analyse. Third, the people filling this questionnaire are kept anonymous. We have not asked for names on the questionnaire to help privacy. The research was conducted between the months of May and July 2018. Simple random sampling method was deployed in selecting participants in this field survey, as it ensures equal as well as independent chances of every

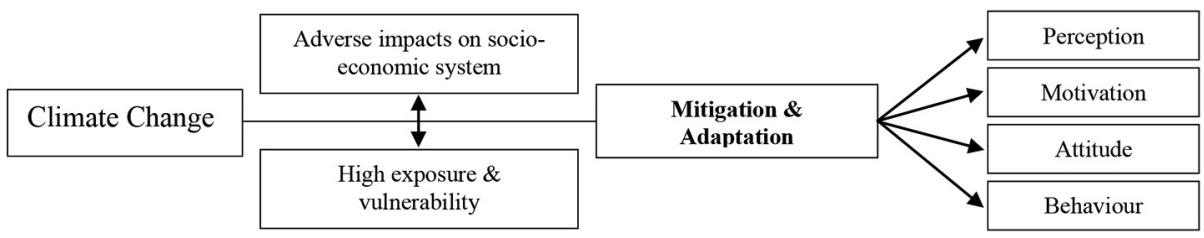

Figure 2. Conceptual framework-CC and associated hazards 
IJCCSM

12,4

482

individual/respondent to be chosen independently while confirming the "external validity" (Edmonds and Kennedy, 2016). Likewise, this technique eases the data collection process when time and cost constraints remain a reality (Olken and Rotem, 1986).

\subsection{Data collection}

Data collection was conducted through a total of 800 individuals, i.e. $n=400$ respondents from Dhaka and Islamabad each. The questionnaire sought to assess respondents' perceptions, attitudes, behaviours and motivations towards climate change in general, and in particular, energy conservation. All such climate changerelated attributes and their resultant impacts on the socio-economic system were studied. It is coupled with individualistic and household mitigative and adaptive strategies that were studied through close-ended questionnaires. This study has targeted both the genders, and the respondents were from diverse educational and income background (Table 1).

The questionnaire was adopted from Semenza et al. (2011), and further modifications were carried out to make it more relevant to study areas and problems. The initial significant questions were related to environmental impacts (i.e. heat waves, frequent wind and storms, water shortages, drought conditions, forest fires, temperature increase), infectious diseases (e.g. dengue, fever, malaria, etc.), flooding disasters, etc. The second question was related to climate change impacts on health (i.e. heat stroke or heat exhaustion, water quality impacts, drowning and sinking, water-borne diseases: cholera, typhoid and dysentery), infectious diseases: dengue, fever, malaria and flu, air quality impacts: respiratory or breathing problems: asthma, etc. Then, questions were related to climate change mitigation and adaptation (i.e. belief in climate change, obstacles and barriers, information available for preparation, motivation, ability, behaviour to protect lives and assets, etc. Further questions were related to energy consumption patterns and attitude towards energy consumption in times of resource scarcity.

\begin{tabular}{lcc}
\hline Demographics & $\begin{array}{c}\text { Dhaka } \\
n=400(\%)\end{array}$ & $\begin{array}{c}\text { Islamabad } \\
n=400(\%)\end{array}$ \\
\hline Gender & & \\
Male & 77 & 61 \\
Female & 23 & 39 \\
Age & & \\
$18-24$ & 32 & 33 \\
$25-44$ & 55 & 53 \\
$>45$ & 13 & 14 \\
Monthly household income & & \\
$<$ US\$300 & 53 & 51 \\
US\$300-US\$600 & 27 & 32 \\
$>$ US\$600 & 20 & \\
Level of education & & 28 \\
Illiterate & 13 & 37 \\
Primary & 15 & 18 \\
Secondary & 34 & 17 \\
Higher education & 38 & \\
& &
\end{tabular}

Table 1.

Respondents' demographic characteristics, 2018 


\subsection{Data interpretation and analysis}

The collected data was coded into binary data ("yes vs no"). For data analysis, statistical package for the social sciences (IBMSPSS Statistics V.21) was used, and initial data analysis was completed through tabulation. For binary dependent variables, the standardised logistic coefficients were projected, as this method remains well suited for scrutinising dichotomous outcomes and is therefore widely used in social science research (Peng and So, 2002). Also, the standardised logistic coefficient method gives the most reliable estimates, especially when the study tries to find the effect of any cause (Engel and MacKinnon, 2007).

\section{Results}

In the first instance, the outcome of this research confirmed that 81 and $90 \%$ of the respondents from Dhaka and Islamabad, respectively, believe in the climate change phenomena and the associated hazards thereof; the participants described heat waves, frequent wind and storm surges in both Dhaka and Islamabad. Moreover, more than $75 \%$ of the population believe that water shortages in both the capitals are the result of climatic changes, whereas only $12 \%$ in Dhaka (compared to $78 \%$ in Islamabad) believe that increased incidents of forest fires in both locations are linked to climatic changes. Further, $95 \%$ of the population in Dhaka, compared to $77 \%$ in Islamabad, believes that the rising of the global mean temperature (GMT) is a sign of climatic change. Also, three-fourth of participants from Dhaka, five out of every seven respondents, confirmed that changing patterns, e.g. cold waves flooding, land sliding, reduced food production, loss of natural habitat for wildlife, etc., are/effects of climate change.

Furthermore, most respondents from Dhaka (nine out of every ten respondents) and five out of every seven respondents in Islamabad linked economic loss to the adverse impact of climate change. Similarly, 92 and $65 \%$ of the respondents from Dhaka and Islamabad, respectively, declared climatic changes as the main reason behind infectious diseases. A comparatively higher proportion $(65 \%)$ from Islamabad attribute aeroallergens to climatic adversity, whereas only $28 \%$ in Dhaka believe this to be the case (Table 2 ).

This study further explored the risks associated with climate change. It is established that local respondents of both capital cities are especially concerned about heat strokes, heat exhaustion, water quality and related adverse effects like infectious diseases. Besides, health issues associated with poor air quality resulting in complications of the respiratory system are concerns for respondents. However, specific health issues related to climate change (like

\begin{tabular}{lcc}
\hline Perceived impacts & Dhaka & Islamabad \\
\hline Heat waves (extended incidents of hot weather patterns) & 0.81 & 0.90 \\
More common wind and storms & 0.70 & 0.77 \\
Water shortages & 0.71 & 0.87 \\
Drought & 0.64 & 0.78 \\
Forest fires & 0.12 & 0.77 \\
GMT increases & 0.95 & 0.58 \\
Cold waves (blizzards) & 0.66 & 0.75 \\
Flooding and landslides (disaster) & 0.75 & 0.72 \\
Reduced food and agronomic production & 0.77 & 0.69 \\
Damage to the habitat of wildlife & 0.81 & 0.65 \\
Economic decline and losses & 0.92 & 0.73 \\
Infectious diseases (e.g. dengue, infection, etc.) & 0.80 & 0.65 Apparent \\
Aeroallergens (pollen) & 0.28 & environmental or \\
climal impacts of
\end{tabular}

Adapting to climate change

483 
IJCCSM

12,4

484

sunburn, cancer and frostbite) are cause for less worry in Dhaka, as only $25 \%$ of the respondents expressed their concerns compared with $60 \%$ of respondents in Islamabad. Lastly, almost $60 \%$ of the respondents described the stress and anxiety they felt related towards climate change (Table 3 ).

This study has further explored the susceptibility at the end of respondents whether climate change affects local people's daily life, especilly if they do not take mitigative measures. It is confirmed by the study's results that $70 \%$ of the respondents' from Dhaka, and $48 \%$ of the respondents from Islamabad, hold the view that, in case of not preparing beforehand, the adverse impacts of climate change could threaten their lives. Furthermore, 90 and $67 \%$ of the respondents from Dhaka and Islamabad, respectively, reported that climate change has the potential to endanger local people's lives by posing adverse effects. However, only $20 \%$ of the respondents from Dhaka, compared to $55 \%$ from Islamabad, are of the impression that timely personal preparation against the adversities of climate change could save their life. It was also confirmed that in total, $68 \%$ of the respondents from both capital cities confirmed the existence of barriers, e.g. no evacuation plans, no emergency kit, no timely information, etc.; this has further increased the vulnerability of the local people to get affected from the negative consequences of climate change (Table 4).

It is also worth considering that less than half of the respondents reported that they not only lack access to timely information to prepare for climate change but cannot also protect themselves against the adversities of climate change. It is found that respondents do not change energy consumption patterns in response to global climate change, as almost $33 \%$ of respondents confirmed the non-existence of evacuation plans at the household level. It was also confirmed that $47 \%$ of the respondents from Dhaka have not possessed an emergency toolkit, which was more alarming in Islamabad, where only $37 \%$ of respondents had such a facility. The participants confirmed the non-existence of prior basic knowledge about how to protect themselves from the harsh conditions brought about by climate change (Table 5). This lack of knowledge was compounded by a lack of skills required for personal protection and the lack of motivation and personal energy to protect oneself ( $48 \%$ in Dhaka and $78 \%$ in Islamabad). A vast majority of more than $75 \%$ confirmed that the non-existence of both financial and other resources, followed by a lack of societal help to mitigate the adverse effects of climate change affects them. Interestingly, almost half $(52 \%)$ of the respondents from Dhaka, compared to $70 \%$ in Islamabad, thought that local peoples' efforts would make no difference - pessimistic local thought in case of Dhaka, whereas, alarmingly half of the respondents in both the cases did not believe in climate change as a fact and its occurrence. Regarding the local populations' trust in their respective national governments, respondents

\begin{tabular}{lcc}
\hline Perceived impacts & Dhaka & Islamabad \\
\hline Heat stroke/fatigue & 0.75 & 0.93 \\
Poor water quality & 0.85 & 0.87 \\
Drowning and sinking & 0.84 & 0.67 \\
Water-borne and vector-borne diseases (e.g. dysentery, etc.) & 0.75 & 0.79 \\
Infectious and transferable diseases (e.g. flu, dengue, etc.) & 0.72 & 0.84 \\
Impacts due to poor air quality & 0.78 & 0.75 \\
Respiratory problems (e.g. asthma) & 0.63 & 0.72 \\
Sunburn & 0.30 & 0.74 \\
Cancer & 0.37 & 0.56 \\
Frostbite & 0.11 & 0.55 \\
Stress, strain and anxiety & 0.62 & 0.59 \\
\hline
\end{tabular}

Table 3.

Apparent health risk associated with climate change

Stress, strain and anxiety 


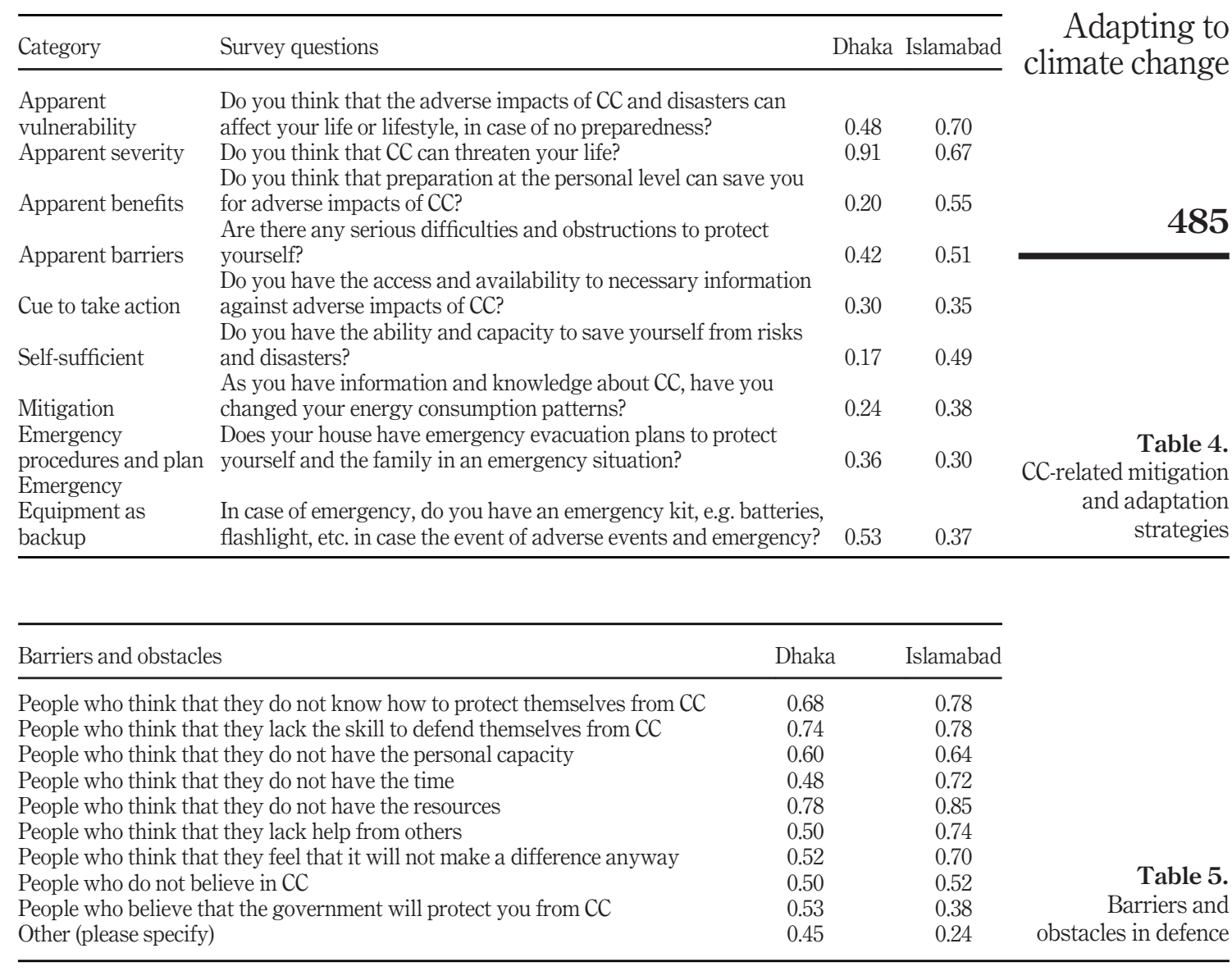

from Dhaka expressed more trust $(53 \%)$ than the respondents in Islamabad, where only $38 \%$ felt that they could rely on the federal government for help and assistance during a climate change (CC)-related disaster.

In the debate, the study further revealed the same level of ignorance, i.e. $65 \%$ - Dhaka and $69 \%$ - Islamabad, against the types of energy consumption that could be effective. The respondents had no idea about the processes that could change the patterns of energy consumption. Furthermore, $52 \%$ of the respondents from Dhaka and $68 \%$ from Islamabad claimed that they do not have the time to reduce energy consumption. Almost $60 \%$ of all the respondents from both the study areas believed that changing energy sources will not make any difference. About half of respondents from Dhaka and over $67 \%$ of the respondents from Islamabad believed that reduction in energy consumption is troublesome, which was followed by 61 and $51 \%$ from Dhaka and Islamabad, respectively, who had firm belief that energy reduction is not their business, but of the government (Table 6).

In an in-depth analysis of the subject matter, this study found that a nominal number of the residents of Dhaka and Islamabad have successfully reduced the household and commercial usage of non-renewable energy sources, e.g. gasoline and petrol. The efforts to 
IJCCSM

12,4

486

buy fuel-efficient cars in both capital cities also remained at the same level. Similarly, the respondents from Dhaka were found to be fonder of walking, bicycling or taking public transport compared to those in Islamabad, who were (comparatively) reluctant to do so. Nearly $48 \%$ of the respondents from Islamabad were found to be more sensitive to waste generation and therefore interested in the recycling of waste. In the same way, $49 \%$ of the respondents from Islamabad, compared to only $23 \%$ from Dhaka, were in favour of a reduction in energy consumption at the household level. In addition, half of the respondents from Dhaka and Islamabad had either bought or switched to a renewable power option for energy production. Lastly, almost $61 \%$ of respondents were sensitive to water conservation than only $23 \%$ in case of Dhaka (Table 7 ).

Similarly, the ratios from the two parallel logistic regression models for both the study areas confirmed that people who believed that climate change can endanger their life were 1.79 times more likely to take mitigation in Dhaka than in Islamabad with 1.80 times of such likelihood. Contra-wise, the susceptibility aspect in case of Dhaka was 1.92 times more likely to use mitigation, whereas more likely 2.90 times in case of Islamabad. Also, people perceived benefits of 5.69 in Dhaka and 1.27 times in Islamabad are more likely to use mitigation. It was also established that barriers to protect themselves from the adversities of climate change were in the range of 6.84 times in case of Dhaka and 5.21 in case of Islamabad. The people who think similarly and have more information about the impacts of climate change were more likely to take mitigative measures like 1.63 times in Dhaka and 1.13 times in Islamabad. Here, people who perceived that they could protect themselves from climate change, their odds of taking mitigation were recorded to be lower by a factor of 0.90 in Dhaka and 0.82 in Islamabad. The results also found that for a certain age, the odds of taking mitigation was lower by $1 \%(1-$ $0.99=0.01)$ in Dhaka and $9 \%$ in Islamabad. The gender-segregated results showed that the males (compared to female gender) were 3.63 times more likely to take mitigation in Dhaka than in Islamabad with a ratio of 1.12 times of such likelihood, whereas the higher-income group was taking more mitigation strategies in both the study areas, as confirmed by the

\begin{tabular}{lcc} 
Steps & Dhaka & Islamabad \\
\hline People who think that they do not know what energy consumption to reduce & 0.65 & 0.69 \\
People who think that they know what to reduce, but no idea how to change them & 0.73 & 0.65 \\
People who think that they do not have the time to reduce your energy consumption & 0.52 & 0.68 \\
People who think that they don't have the money to reduce your energy consumption & 0.74 & 0.76 \\
People who think that they feel that a reduction in energy consumption will not make a & & 0.61 \\
difference & 0.49 & 0.59 \\
People who think that they are inconvenient to reduce your energy consumption & 0.61 & 0.51 \\
People who think that they do not believe reducing energy consumption & &
\end{tabular}

Table 6.

Steps to reduce energy consumption

\begin{tabular}{llc}
\hline Mitigative steps & Dhaka & Islamabad \\
\hline Decrease the amount of gasoline & 0.30 & 0.32 \\
Bought fuel-efficient car & 0.50 & 0.41 \\
Started using public transportation, walking, bicycling or carpooling & 0.70 & 0.55 \\
Started recycling waste & 0.11 & 0.48 \\
Decreased energy consumption & 0.23 & 0.49 \\
Switched to renewable energy options & 0.50 & 0.52 \\
Conserved water at home & 0.23 & 0.61 \\
\hline
\end{tabular}

Table 7.

Attitudes towards energy conservation

Conserved water at home 
study's results, where people with higher education were 1.57 times more likely to take mitigation in Dhaka and 1.64 were more likely in Islamabad (Table 8).

The results of the ratios from the logistic regression model for the "adaptation" confirmed that those in Dhaka who believe that "climate change could endanger their life" are 1.56 times more likely to use adaptation strategies such as having an emergency tool kits and 1.47 times more likely to use adaptation strategies in Islamabad. People perceived susceptibilities are 2.72 and 2.65 times more likely to use adaptation in Dhaka and Islamabad, respectively. People perceived benefits are 1.61 times more likely to make adaptations in Dhaka and 1.30 more likely climate change to use mitigation in Islamabad. People perceived barriers to protect themselves are 1.04 times more likely to use adaptation in Dhaka and 2.55 times more likely to use adaptation in Islamabad. People having more information about the impact of CC are 2.39 times more likely to use adaptation in case of Dhaka than the likelihood of 2.19 times in Islamabad. People who perceived that they could protect themselves from $\mathrm{CC}$, their odds of using adaptation strategies are higher by a factor of 1.12 in the study area of Dhaka, and 1.34 in Islamabad. The age segregation effect showed that within a certain age, the odds of using adaptation are lower by $25 \%(1-0.75=0.25)$ in Dhaka and higher by $70 \%$ in Islamabad. Hence, the males were using less adaptation by $8 \%$ in Dhaka, while in Islamabad 1.01 times more males were likely to use such adaption strategies. Income-segregated results confirmed that the higher-income group is more likely to have an emergency toolkit (by factor 1.06) in Dhaka and (2.04) in Islamabad and people with higher education had more emergency toolkits, i.e. $64 \%$ in Dhaka and $52 \%$ in Islamabad (Table 8).

\section{Discussion}

Interestingly, most of the population in both the capital cities have a firm belief in the CC phenomena. It shows their awareness level and changed perception against climatic hazards, which are significantly rising in the global societies and posing hazardous impacts (e.g. heat waves, wind, storm surges etc.) on the local societies (Schofield, 2011). Likewise, the trend that the mainstream studied populace is conscious about the water scarcity issues of the regions is in line with other studies and which also remains the main issue or a topic of a central position in the world politics (Khalid et al., 2014). Hence, like other world societies, which are haunted and affected by the changing climatic patterns (Urry, 2015), the locality of Dhaka and Islamabad is sensitised by the potential danger affecting local people's lives. It is followed by crucial community' sensitisation and the perception (of three-fourth of the

\begin{tabular}{|c|c|c|c|c|c|}
\hline \multirow[b]{2}{*}{ Variables } & \multicolumn{2}{|c|}{ Dhaka } & \multicolumn{2}{|c|}{ Islamabad } & \\
\hline & Mitigation & Adaptation & Mitigation & Adaptation & \\
\hline Severity & $1.79 *$ & $1.56^{*}$ & $1.80 *$ & $1.47 *$ & \\
\hline Susceptibility & $1.92 * *$ & $2.72 * *$ & $2.90 * *$ & $2.65^{* * *}$ & \\
\hline Benefits & $5.69 * * *$ & 1.61 & 1.27 & 1.30 & \\
\hline Barriers & $6.84 * * *$ & $1.04 *$ & $5.21 * * *$ & $2.55^{*}$ & \\
\hline Cues to action & 1.63 & $2.39 *$ & 1.13 & 2.19 & \\
\hline Self-efficacy & $0.90 * * *$ & $1.12 *$ & $0.82 * * *$ & $1.34^{*}$ & \\
\hline Age & $0.99 *$ & $0.75^{*}$ & $0.91 *$ & 1.70 & \\
\hline Gender & $3.64 * * *$ & 0.92 & $1.12 *$ & $1.01 * *$ & \\
\hline Income & 1.07 & 1.06 & $1.19 * *$ & $2.04 * *$ & \\
\hline Education & $1.57 * *$ & $1.64^{* * * *}$ & $1.64^{*}$ & $1.52^{*}$ & $\begin{array}{r}\text { Table } 8 . \\
\text { Logistic }\end{array}$ \\
\hline \multicolumn{5}{|c|}{ Notes: $* * *$ is significant at $99 \% * * * 95 \% * * 90 \%$} & regression model \\
\hline
\end{tabular}


IJCCSM

12,4

488

studies population) about the global and regional adversities on agriculture or food production (Chen et al., 2013) and the natural habitat, as well as the wildlife (Ehrlich and Pringle, 2008; Botkin et al., 2007).

The natural hazards are also hampering the economic system of both the capitals that were studied. These localised economic losses that are due to loss of livelihood opportunities remain a global phenomenon (Deen, 2015), where the global societies are facing degradation of economic capital due to loss of agricultural production, damage to livestock, loss of income and damage to household's physical infrastructure (Analytica, 2010), and that leads to rise in poverty (Khan, 2013). Similarly, the sufferings of the local populace of both Dhaka and Islamabad from the infectious diseases contribute to the global rise in diseases (Harvell et al., 2002; Lafferty, 2009; Okamura and Feist, 2011), coupled with stress and anxiety; this poses major concerns for both the regional and global authorities to take practical actions of control and prevention. The limited national action by the responsible government bodies has created concerns amongst the local societies, as they lack means of preparation to minimise the climatic threats harming their lives. This local concern is not aligned to changing the global trend, where the national government's has an increasing responsibility to prepare and adapt CC-resilient planning for safeguarding the inhabitants (Baker et al., 2012). So, the government authorities in the underdeveloped countries are still not duly responsive to help the local affected population as the locality confirmed existence of barriers like, no emergency kit, no timely information, etc., which further increases the locals' vulnerability.

In this distressing situation, the urge to create an awareness for community-based mitigation and adaptation is enlarging, especially in the least developed countries (Mbow et al., 2014). This can become possible because the local communities can plan better, based on resources, that build their resilience against climatic hazards (McCarthy et al., 2001). However, this study has found astringent to the international focus of community-based mitigation and adaptation as the studies population lacks basic knowledge, as well as financial resources to plan to protect themselves, which questions the role of the federal government in both the countries and other similar cases internationally. Furthermore, the study findings show a non-existence of societal fabric (i.e. trust and cooperation) construct an alarming situation for the third-world societies because individualistic strategies cannot guarantee public safety. In this situation, the community of Islamabad is alarmingly less confident than in case of Dhaka, for timely assistance in disastrous situations. Lastly, interestingly, unlike Dhaka, almost half of the population in Islamabad is in favour of a reduction in energy consumption at the household level - a mitigative strategy, yet almost $60 \%$ of the capitals' population believe that it will not make any difference. This reported community psychology of non-conservation of energy is profoundly established based on insufficient knowledge, perceptions, low priority, high prices and non-existence of alternative (non-fossil fuel) energy sources (Steg, 2008) and is affecting adaption against the energy course in both Dhaka and Islamabad.

Intentional reduction in energy consumption by individuals hinges on their state of awareness and concern about climate change, their willingness to act and their ability to change. Thus, it is essential to portray voluntary mitigation as necessary and achievable (Semenza et al., 2011). There is not only need of low-impact energy conservation (e.g. switching off lights; driving less; switching to a fuel-efficient car or appliance), but to focus on high energy savings as well (e.g. flying less, driving less and walking more).

\section{Conclusion}

The study concluded that the majority of the population in both the capital cities; Dhaka, Bangladesh, and Islamabad, Pakistan, hold a firm belief in the dangers of $\mathrm{CC}$ and its 
associated hazards, e.g. heat waves, storm surges, forest fires, rise in temperature, landslides, food insecurity, loss of natural habitat for wildlife, heat strokes, heat exhaustion, water quality issues and an upsurge of infectious diseases. It is coupled with the potential of the climatic hazards that can endanger local people's lives. The discrepancies exist between the studied cities where the relatively higher population as in case of Islamabad perceived that timely preparation can save themselves. Alarmingly, the study established nonexistence of evacuation plans (e.g. emergency kit etc.) in both the capital cities, coupled with a lack of personal/individualistic skills for personal protection, which if exists, the locality is not motivated towards its applicability. It suggests also that as a reality the poor societies, like in this case, face financial constraints that hinder societal mitigation and adaptation attempts in emergencies. These conclusions reinforce the existing literature revealing the similar patterns in South Asia (Knox et al., 2012; Sivakumar and Stefanski, 2010; Singh et al., 2014), which questions the limited role of national and local governments in the area (Ojha et al., 2014; Ahmed and Suphachalasai, 2014). So, this study's outcomes alarm the persistence of issues in the present times.

The persistent scenario calls for national emergencies in both Bangladesh and Pakistan to analyse these regional impacts with the ones highlighted by intergovernmental panel on climate change (Betsill and Bulkeley, 2013) so that (federal and local) governments' actions can be accelerated to safeguard vulnerable societies and regions in South Asia and in other undeveloped localities. It is established from this study that the educated class remained less adaptive in the study areas; the male gender was more involved in the mitigative measures than their female counterparts. It reflects that education is not synonyms to sensitisation. So, there remains a dire need to sensitise the educated population, particularly the females, to contribute to the planning and execution of mitigative and adaptive strategies. Here, the strategies highlighted by Shepard et al. (2018) and Oyero et al. (2018) are exclusively found relevant to achieve virtuous results in backward societies. The government also needs to provide timely information, as well as emergency toolkits because the underprivileged societies lack affordable capacities.

\section{Limitations of the study and futuristic research potential}

Lack of financial resources has hindered to extend this study to other capital cities in South Asia and the inclusion of advanced and underdeveloped capitals in the South Asia region for broad-based comparison.

The extension of this research can be based on similar questions across the South Asian region. The extension of this study's pattern of cross-comparisons between the capitals of underdeveloped and developed (i.e. European) countries would give new insight to see the stance of societies, localised mitigative and adaptive strategies, (federal and local) government role, etc. Likewise, the third potential area can be based on the political, economic, climatic regime (separately or all together), that can influence the common low perception, motivation and limited mitigative and adaptive strategies that enlarge the extent of climatic hazards and what needs to done in this regard.

\section{Notes}

1. Natural disasters are the phenomenon that impact the normal business of the global and regional societies. It is classified into six groups; geophysical (e.g. earthquake) meteorological (e.g. extreme temperature, storm etc.), hydrological (e.g. flood, landslide etc.), climatological (drought, wildfire etc.), biological (epidemic, etc.) and extra-terrestrial (space weather, etc.) (see: CBSE (2006), "Natural Hazards and Disaster Management", Delhi, Preet Vihar., Central Board of Secondary Education. India, D. Guha-Sapir, R. B., Ph. Hoyois - EM-DAT (2015), "International Disaster Database", in Louvain, U. C. d. (Ed., Brussels, Belgium). 


\section{IJCCSM}

12,4

2. Vulnerability is often projected in negative terms. It is in which our (non-)natural system is susceptible to hazards, where it is unable to cope with adversities (see: McCarthy, J. J., Canziani, O. F., Leary, N. A., Dokken, D. J. and White, K. S. (2001), Climate change 2001: impacts, adaptation, and vulnerability: contribution of Working Group II to the third assessment report of the Intergovernmental Panel on Climate Change, Cambridge University Press.. Here, vulnerability is studied in connection with the socio-economic conditions of the people that set the intensity of any hazard.

3. Mitigation is a reactive response of the societies against the climatic hazards that destroy their life system. It is based on a detailed assessment of costs and potentials of implementation (see: Metz, B., Davidson, O., Bosch, P., Dave, R. and Meyer, L. (2007), Climate change 2007: Mitigation of climate change, Cambridge Univ. Press.)

4. Adaptation is referred to as all appropriate actions taken to minimise and prevent the damages by any cause (here, natural hazards) after having anticipating their adversities.

\section{References}

Abuzar, M.K., Ahmad, B., Sheikh, R.A., Kiran, R., Manzoor, R. and Tul Kubra, S. (2016), "Diagnostic study of heavy downpour in 2015 flash floods over Chitral area", Northern Pakistan, Vol. 12, p. 24

Adger, W.N. (2006), "Vulnerability”, Global Environmental Change, Vol. 16 No. 3, pp. 268-281.

Adger, W.N. (2010), "Social capital, collective action, and adaptation to climate change", Der Klimawandel, Springer, pp. 327-345.

Ahmed, I. (2015), People of Many Rivers: Tales from the Riverbanks, University Press Limited, Dhaka, Bangladesh.

Ahmed, M. and Suphachalasai, S. (2014), Assessing the Costs of Climate Change and Adaptation in South Asia, Asian Development Bank.

Akintunde, E.A. (2017), "Theories and concepts for human behavior in environmental preservation", Journal of Environmental Science and Public Health, Vol. 1 No. 2, pp. 120-133.

Alam, G. (2016), An Assessment of the Livelihood Vulnerability of the Riverbank Erosion Hazard and Its Impact on Food Security for Rural Households in Bangladesh, University of Southern Queensland.

Alam, G.M. (2017), "Livelihood cycle and vulnerability of rural households to climate change and hazards in Bangladesh", Environmental Management, Vol. 59 No. 5, pp. 777-791.

Alam, G.M., Alam, K. and Mushtaq, S. (2016), "Influence of institutional access and social capital on adaptation decision: empirical evidence from hazard-prone rural households in Bangladesh", Ecological Economics, Vol. 130, pp. 243-251.

Analytica, O. (2010), "Pakistan: Floods imperil long term prospects", SMDC (2010a). Super Flood of Pakistan, SAARC Newsletter, Disaster Management Centre, New Delhi, p. 1.

Ayers, J. and Forsyth, T. (2009), "Community-based adaptation to climate change”, Environment: science and Policy for Sustainable Development, Vol. 51 No. 4, pp. 22-31.

Baker, I., Peterson, A., Brown, G. and McAlpine, C. (2012), "Local government response to the impacts of climate change: an evaluation of local climate adaptation plans", Landscape and Urban Planning, Vol. 107 No. 2, pp. 127-136.

Bandura, A. (2006), "Guide for constructing self-efficacy scales", Self-Efficacy Beliefs of Adolescents, Vol. 5 No. 1, pp. 307-337.

Beck, N. and Kieser, A. (2003), "The complexity of rule systems, experience and organizational learning", Organization Studies, Vol. 24 No. 5, pp. 793-814.

Betsill, M. and Bulkeley, H. (2013), Cities and Climate Change, Routledge. 
Betzold, C. (2015), “Adapting to climate change in small island developing states", Climatic Change, Vol. 133 No. 3, pp. 481-489.

Botkin, D.B., Saxe, H., Araujo, M.B., Betts, R., Bradshaw, R.H., Cedhagen, T., Chesson, P., Dawson, T.P., Etterson, J.R. and Faith, D.P. (2007), "Forecasting the effects of global warming on biodiversity", BioScience, Vol. 57 No. 3, pp. 227-236.

CBSE (2006), Natural Hazards and Disaster Management, Central Board of Secondary Education, Delhi, Preet Vihar.

Chau, M.M., Reyes, W.R. and Ranker, T.A. (2013), "Ecological factors influencing growth of the endangered Hawaiian fern Marsilea Villosa (marsileaceae) and implications for conservation management", American Journal of Botany, Vol. 100 No. 8, pp. 1532-1543.

Chen, Y., Wu, Z., Okamoto, K., Han, X., Ma, G., Chien, H. and Zhao, J. (2013), “The impacts of climate change on crops in China: a Ricardian analysis", Global and Planetary Change, Vol. 104, pp. 61-74.

Clarke, T., McNamara, K.E., Clissold, R. and Nunn, P.D. (2019), “Community-based adaptation to climate change: lessons from Tanna Island, Vanuatu”, Island Studies Journal, Vol. 14 No. 1.

Deen, S. (2015), "Pakistan 2010 floods. Policy gaps in disaster preparedness and response", International Journal of Disaster Risk Reduction, Vol. 12, pp. 341-349.

Dhiman, R.C., Pahwa, S., Dhillon, G. and Dash, A.P. (2010), "Climate change and threat of vector-borne diseases in India: are we prepared?", Parasitology Research, Vol. 106 No. 4, pp. 763-773.

Edmonds, W.A. and Kennedy, T.D. (2016), An Applied Guide to Research Designs: Quantitative, Qualitative, and Mixed Methods, Sage Publications.

Ehrlich, P.R. and Pringle, R.M. (2008), "Where does biodiversity go from here? A grim business-asusual forecast and a hopeful portfolio of partial solutions", Proceedings of the National Academy of Sciences, Vol. 105 No. S-1, pp. 11579-11586.

Engel, B.T. and MacKinnon, J.R. (2007), Enhancing Human Occupation through Hippotherapy: A Guide for Occupational Therapy, AOTA Press.

Furgal, C., Martin, D., and Gosselin, P. (2002), "Climate change and health in Nunivak and Labrador: lessons from Inuit knowledge", The Earth is Faster Now: Indigenous Observations of Arctic Environmental Change, Arctic Research Consortium of the United States.

GeoDetos (2018), Geographic Coordinates of Islamabad, Pakistan, GeoDetos.

GoB (2010), Comprehensive Disaster Management Programme, Phase II (2010-14), Ministry of Food and Disaster, Government of Bangladesh, Dhaka.

Gregory, R.I., Yan, K-P., Amuthan, G., Chendrimada, T., Doratotaj, B., Cooch, N. and Shiekhattar, R. (2004), "The microprocessor complex mediates the genesis of microRNAs", Nature, Vol. 432 No. 7014, pp. 235-240.

Harvell, C.D., Mitchell, C.E., Ward, J.R., Altizer, S., Dobson, A.P., Ostfeld, R.S. and Samuel, M.D. (2002), "Climate warming and disease risks for terrestrial and marine biota", Science, Vol. 296 No. 5576, pp. 2158-2162.

Kaise, F., Wolfing, S. and Fuhrer, U. (1999), "Environmental attitude and ecological behavior”, Journal of Environmental Psychology, Vol. 19 No. 1, pp. 1-19.

Khalid, I., Mukhtar, A. and Ahmed, Z. (2014), "Water scarcity in South Asia: a potential conflict of future decades", Journal of Political Studies, Vol. 21 No. 1.

Khan, A.N. (2013), "Analysis of 2010-flood causes, nature and magnitude in the Khyber Pakhtunkhwa, Pakistan”, Natural Hazards, Vol. 66 No. 2, pp. 887-904.

Knox, J., Hess, T., Daccache, A. and Wheeler, T. (2012), "Climate change impacts on crop productivity in Africa and South Asia", Environmental Research Letters, Vol. 7 No. 3, p. 034032

Lafferty, K.D. (2009), "The ecology of climate change and infectious diseases”, Ecology, Vol. 90 No. 4, pp. 888-900. 
IJCCSM 12,4

Latitude (2015), "Latitude and longitude of Dhaka”, Bangladesh, available at: https:/latitude.to/map/ $\mathrm{bd} / \mathrm{bangladesh} / \mathrm{cities} / \mathrm{dhaka}$

McCarthy, J.J., Canziani, O.F., Leary, N.A., Dokken, D.J. and White, K.S. (2001), Climate change 2001: impacts, adaptation, and vulnerability: contribution of Working Group II to the third assessment report of the Intergovernmental Panel on Climate Change, Cambridge University Press.

McCusker, B. and Carr, E.R. (2006), "The co-production of livelihoods and land use change: Case studies from South Africa and Ghana", Geoforum, Vol. 37 No. 5, pp. 790-804.

McMichael, A. and Woodruff, R. (2004), Climate Change and Risk to Health, British Medical Journal Publishing Group.

McMichael, A.J. and Kovats, R.S. (2000), "Climate change and climate variability: adaptations to reduce adverse health impacts", Environmental Monitoring and Assessment, Vol. 61 No. 1, pp. 49-64.

McNamara, K.E. (2013), "Taking stock of community-based climate-change adaptation projects in the pacific", Asia Pacific Viewpoint, Vol. 54 No. 3, pp. 398-405.

Mbow, C., Smith, P., Skole, D., Duguma, L. and Bustamante, M. (2014), “Achieving mitigation and adaptation to climate change through sustainable agroforestry practices in Africa”, Current Opinion in Environmental Sustainability, Vol. 6, pp. 8-14.

OCHA (2010), Ten Biggest Natural Disasters in Pakistan: By Number of Affected Population, The United Nations Office for the Coordination of Humanitarian Affairs, New York, NY.

Ojha, H.R., Sulaiman V, R., Sultana, P., Dahal, K., Thapa, D., Mittal, N., Thompson, P., Bhatta, G.D., Ghimire, L. and Aggarwal, P. (2014), "Is South Asian agriculture adapting to climate change? Evidence from the Indo-Gangetic plains", Agroecology and Sustainable Food Systems, Vol. 38 No. 5, pp. 505-531.

Okamura, B. and Feist, S.W. (2011), "Emerging diseases in freshwater systems", Freshwater Biology, Vol. 56 No. 4, pp. 627-637.

Olken, F. and Rotem, D. (1986), Simple Random Sampling from Relational Databases, Computer Science Research Department, University of CA. Lawrence Berkeley Laboratory, Berkeley, CA, No. LBL20707. Condensed, pp. 1-16.

Oyero, O., Oyesomi, K., Abioye, T., Ajiboye, E. and Kayode-Adedeji, T. (2018), "Strategic communication for climate change awareness and behavioural change in Ota local government of Ogun state", African Population Studies, Vol. 32 No. 1,

Peng, C.-Y.J. and So, T.-S.H. (2002), "Logistic regression analysis and reporting: a primer", Understanding Statistics, Vol. 1 No. 1, pp. 31-70.

Rollinson, D. (2008), Organisational Behaviour and Analysis: An Integrated Approach, Pearson Education.

Schellnhuber, H.J., Hare, B., Serdeczny, O., Schaeffer, M., Adams, S., Baarsch, F., Schwan, S., Coumou, D., Robinson, A. and Vieweg, M. (2013), "Turn down the heat: climate extremes, regional impacts, and the case for resilience", Turn down the Heat: climate Extremes, Regional Impacts, and the Case for Resilience.

Schofield, N. (2011), "Climate change and its impacts-current understanding, future directions", Basin Futures: water Reform in the Murray-Darling Basin, pp. 81-98.

Semenza, J.C., Hall, D.E., Wilson, D.J., Bontempo, B.D., Sailor, D.J. and George, L.A. (2008), "Public perception of climate change: voluntary mitigation and barriers to behavior change", American Journal of Preventive Medicine, Vol. 35 No. 5, pp. 479-487.

Semenza, J.C., Ploubidis, G.B. and George, L.A. (2011), "Climate change and climate variability: personal motivation for adaptation and mitigation”, Environmental Health, Vol. 10 No. 1, p. 46.

Shahid, S. and Behrawan, H. (2008), "Drought risk assessment in the Western part of Bangladesh", Natural Hazards, Vol. 46 No. 3, pp. 391-413. 
Shepard, S., Boudet, H., Zanocco, C.M., Cramer, L.A. and Tilt, B. (2018), "Community climate change beliefs, awareness, and actions in the wake of the September 2013 flooding in boulder county, Colorado", Journal of Environmental Studies and Sciences, Vol. 8 No. 3, pp. 312-325.

Singh, P., Nedumaran, S., Boote, K.J., Gaur, P., Srinivas, K. and Bantilan, M. (2014), "Climate change impacts and potential benefits of drought and heat tolerance in chickpea in South Asia and East Africa”, European Journal of Agronomy, Vol. 52, pp. 123-137.

Sivakumar, M.V. and Stefanski, R. (2010), "Climate change in South Asia”, Climate Change and Food Security in South Asia, Springer, pp. 13-30.

Steg, L. (2008), "Promoting household energy conservation", Energy Policy, Vol. 36 No. 12, pp. 4449-4453.

Urry, J. (2015), "Climate change and society”, Why the Social Sciences Matter, Springer, pp. 45-59.

WB (2013), "Turn down the heat: climate extremes, regional impacts, and the case for resilience", $A$ Report for the World Bank by the Potsdam Institute for Climate Impact Research and Climate Analytics, World Bank.

WDR (2003), "World Disasters Report", International Federation of Red Cross and Red Crescent Societies, Geneva.

Wiley, L.F. and Gostin, L.O. (2009), “The international response to climate change: an agenda for global health", JAMA, Vol. 302 No. 11, pp. 1218-1220.

\section{Further reading}

Guha-Sapir, D., Below, R. and Hoyois, P. (2015), International Disaster Database, in Louvain, U. (Ed.) Catholic University of Louvain, Brussels, Belgium.

Metz, B., Davidson, O., Bosch, P., Dave, R., and Meyer, L. (2007), Climate Change 2007: Mitigation of Climate Change, Cambridge University Press.

\section{About the author}

Shahzad Alvi is a PhD Fellow at the Department of Economics, School of Social Sciences and Humanities (S3H), National University of Sciences and Technology (NUST), Islamabad, Pakistan. He received his Master's in Economics from the same university. He has published many papers in toptier journals such as Energy Reports; Heliyon; Weather, Climate and Society; European Journal of Sustainable Development; Indian Economic Review. He credits development of an integrated assessment model for Food Security for South Asia under climate change. Mr Alvi is the Founder of the International Center of Economic Policy and Sustainability Sciences (CEPSS). He is also a Visiting Fellow at National Defense University, Pakistan.

Dr Umer Khayyam is currently serving as Assistant Professor and Head of Department of Development Studies, School of Social Sciences and Humanities (S3H), National University of Sciences and Technology (NUST), Islamabad, Pakistan. He received his PhD from the University of Münster, Germany, and Master from the University of Applied Sciences, Osnabrück, Germany. His research interests include: development studies: genesis, theories and practice and human dimension of climate change. He publishes regularly in the top-tier journals, newspapers and magazines. He is also the Editor of NUST Journal of Social Sciences and Humanities (NJSSH) and reviewer of several international journals. Umer Khayyam is the corresponding author and can be contacted at: dr. umer@s3h.nust.edu.pk

For instructions on how to order reprints of this article, please visit our website:

www.emeraldgrouppublishing.com/licensing/reprints.htm

Or contact us for further details: permissions@emeraldinsight.com 